\title{
TNM staging of midgut and hindgut (neuro) endocrine tumors: a consensus proposal including a grading system
}

\author{
G. Rindi • G. Klöppel • A. Couvelard • P. Komminoth • \\ M. Körner • J. M. Lopes • A-M. McNicol • O. Nilsson • \\ A. Perren • A. Scarpa $\cdot$ J-Y. Scoazec $\cdot$ B. Wiedenmann
}

Received: 18 May 2007 /Revised: 14 June 2007 / Accepted: 14 June 2007 / Published online: 3 August 2007

(C) Springer-Verlag 2007

\begin{abstract}
Criteria for the staging and grading of neuroendocrine tumors (NETs) of midgut and hindgut origin were established at the second Consensus Conference in Frascati (Rome) organized by the European Neuroendocrine Tumor Society (ENETS). The proposed tumor-node-metastasis (TNM) classifications are based on the recently published ENETS Guidelines for the Diagnosis and Treatment of gastroenteropancreatic NETs and follow our previous proposal for foregut tumors. The new TNM classifications for NETs of the ileum, appendix, colon, and rectum, and the grading system were designed, discussed, and consensually
\end{abstract}

G. Rindi

Department of Pathology, University of Parma,

Parma, Italy

\section{G. Klöppel}

Department of Pathology, University of Kiel,

Kiel, Germany

\section{A. Couvelard}

Department of Pathology, Hôpital Beaujon,

Clichy, France

P. Komminoth

Department of Pathology, Stadspital Triemli,

Zürich, Switzerland

\section{Körner}

Department of Pathology, University of Bern,

Bern, Switzerland

\section{J. M. Lopes}

Department of Pathology, Porto Medical School \& IPATIMUP, University of Porto,

Porto, Portugal

\section{A.-M. McNicol}

Department of Pathology, Glasgow Royal Infirmary,

Glasgow, Scotland, UK approved by all conference participants. These proposals need to be validated and are meant to help clinicians in the stratification, treatment and follow-up of patients.

Keywords Neuroendocrine tumors · Ileum · Appendix · Colon $\cdot$ Rectum $\cdot$ Staging $\cdot$ TNM $\cdot$ Grading $\cdot$ Mitotic index . Ki-67 index

List of the participants (front authors excluded) in the "Consensus Conference on the ENETS Guidelines for the Diagnosis and Treatment of Neuroendocrine Gastrointestinal Tumors, Part 2: Midgut and Hindgut Tumors" held in Frascati (Rome, Italy), November 1-4, 2006.

\section{O. Nilsson}

Department of Pathology, Gothenborg University, Gothenborg, Sweden

\author{
A. Perren \\ Department of Pathology, Klinikum rechts der Isar, \\ Munich, Germany
}

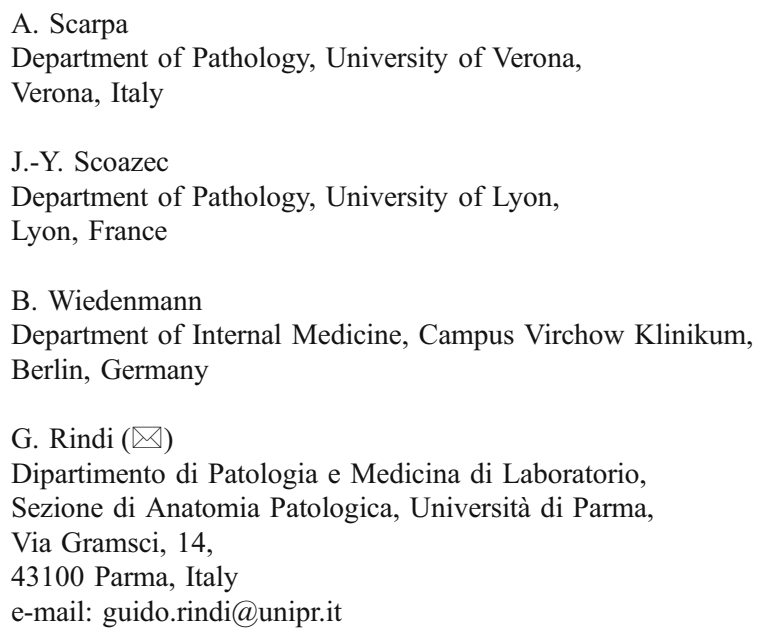


Håkan Ahlman, Institute for Surgical Sciences, Dept. of Surgery, Sahlgrenska sjukhuset, S-41345 Gothenborg (Sweden); Rudolf Arnold, Wittelsbacherstr. 6, 80469 Münich (Germany); Christoph Auernhammer, Medizinische Klinik II, Grosshadern Klinikum der Ludwig-Maximilians-Universität München, Marchioninistr. 15, 81377 Münich (Germany); Martyn Caplin, Royal Free Hospital London, Centre for Gastroenterology, London NW3 2QG (UK); Emanuel Christ, Endokrinologie für Erwachsene, Inselspital, Freiburgstrasse, CH-3010 Bern (Switzerland); Wouter de Herder, Department of Internal Medicine, Section of Endocrinology, Erasmus MC, Dr. Molewaterplein 40, 3015 GD Rotterdam (The Netherlands); Gianfranco Delle Fave, Ospedale S. Andrea, Via di Grottarossa 1035, 00189 Rome (Italy); Barbro Eriksson, Medical Department, Endocrine Unit, University Hospital, S-75185 Uppsala (Sweden); Massimo Falconi, University of Verona, Medicine and Surgery, General Surgery Section, MED/18 General Surgery, Via dell'Artigliere 8, 37129 Verona, (Italy); Diego Ferone, Departments of Internal Medicine and Endocrinological and Metabolic Sciences, University of Genoa, 16132 Genoa (Italy); Peter Goretzki, Städtisches Klinikum Neuss, Lukas-Krhs., Chirurgische Klinik I, Preussenstr. 84, 41456 Neuss (Germany); David Gross, Dep. of Endocrinology \& Metabolism, Hadassah University Hospital, 91120 Jerusalem (Israel); Rudolf Hyrdel, University Hospital Martin, II. Internal med. dept., Kollarova 2 (street), SVK 036 59, Martin, (Slovakia); Robert Jensen, National Institutes of Health, Cell Biology Section, Building 10, Room 9C-193, Bethesda, MD, (USA); Gregory Kaltsas, G. Genimatas Hospital, Mesogion Ave., 10443 Athens (Greece); Fahrettin Keleștimur, Erciyes University Medical School, Department of Endocrinology and Metabolism, 38039 Kayseri (Turkey); Reza Kianmanesh, UFR BichatBeaujon-Louis Mourier, Service de Chirurgie Digestive, Hôpital Louis Mourier, 178 Rue des Renouillers, 92700 Colombes (France); Wolfram Knapp MHH, Klinik für Nuklearmedizin, Carl-Neuberg-Str. 1, 30625 Hannover, (Germany); Ulrich-Peter Knigge, Dept. of Surgery, C 2122, Rigshospitalet Blegdamsuej, DK-2100 Copenhagen (Denmark); Beata Kos-Kudta, Slaska Akademia Medyczna, Klinika Endokrynologii, ul. 3 Maja 13/15, 41-800 Zabrze (Poland); Eric Krenning, Erasmus MC, Dr Molewaterplein 40, 3015G, Rotterdam (The Netherlands); Matthew Kulke, Dana-Farber Cancer Institute, 44 Binney Street, Dana 1220, Boston, MA 02115 (USA); Larry Kvols, H. Lee Moffitt Cancer Center/ University of South Florida, Magnolia Drive 12902, Tampa, FL, 33612 (USA); Dik J. Kwekkeboom, Department of Nuclear Medicine, Erasmus University Medical Center, Dr. Molewaterplein 40, 3015 GD Rotterdam (The Netherlands); Riccardo Manfrodi, Istituto di Radiologia, Policlinico GB Rossi, Piazzale LA Scuro, 37134 Verona (Italy); Bruno Niederle, Universität Wien, Abt. Chirurgie, Allgemeines Krankenhaus Wien, Währinger Gürtel 18-20, Ebene 3L, A-1090 Vienna (Austria); George Nikou, 68, Plataion St, 15235 Vrilissia, Athens (Greece); Ola Nilsson, Dept. of Pathology, Sahlgrenska sjukhuset, S-41345 Gothenborg (Sweden); Kjell Öberg, Dept. of Internal Medicine, Endocrine Unit, University Hospital, S-75185 Uppsala (Sweden); Juan O'Connor, Instituto Alexander Fleming, Crámer 1180, C1426ANZ, Buenos Aires (Argentina); Dermot O'Toole, Service de Gastroentérologie, Centre Hospitalier Universitaire d'Angers, 49000 Angers (France); Ulrich-Frank Pape, Charité Universitäts Medizin, Department of Internal Medicine, Division of Hepatology and Gastroenterology, Campus Virchow Klinikum, Augustenburger Platz 1, 13353 Berlin, (Germany); Marianne Pavel, Medizinische Klinik I, Universitätsklinikum Erlangen, Krankenhausstr. 12, 91054 Erlangen (Germany); Ursula Plöckinger, Charité Universitäts Medizin, Campus Virchow-Klinikum, Department of Hepatology and Gastroenterology, Augustenburger Platz 1, 13353 Berlin (Germany); John Ramage, Dept of Gastroenterology, North Hamsphire Hospital, Aldermaston Rd, Basingstoke, RG249NA, Hampshire (UK); Jens Ricke, Otto-von-Guericke-Universität Magdeburg, Klinik für Radiologie und Nuklearmedizin, Leipziger Str. 44, 29120 Magdeburg, (Germany); Philippe Ruszniewski, Service de Gastroentérologie, Hôpital Beaujon, 100, avenue de Général Leclerc, 92118 Clichy (France); Ramon Salazar,
Institut Català d'Oncologia, Av. Gran Via s/n, 08907 Barcelona (Spain); Maria Isabel Sevilla Garcia, Hospital Virgen de la Victoria, C/Colonia Santa Ines s/n, 29010 Malaga (Spain); Thomas Steinmüller, Vivantes Humboldt-Klinikum, Chirurgische Klinik, Am Nordgraben 2, 13509 Berlin, (Germany); Anders Sundin, Uppsala University Hospital, Department of Radiology, SE 751-85, Uppsala (Sweden); Babs Taal, Netherlands Cancer Centre, Plesmanlaan 121, 1066 (CX) Amsterdam (The Netherlands); Marie-Pierre Vullierme, Service de Radiologie, Hôpital Beaujon, 100, avenue de Général Leclerc, 92118 Clichy (France); Stefan Wildi, University Hospital of Zürich, Dept. of Visceral and Transplantation Surgery, CH-8091 Zürich (Switzerland); James C. Yao, The University of Texas M. D. Anderson Cancer Center, 1515 Holcombe Boulevard, Houston, TX 77030 (USA).

\section{Background}

Based on recognized differences in morphology, function and clinical behavior $[1,2,21,30]$, the current WHO classification provides a prognosis-oriented definition of gastroenteropancreatic neuroendocrine tumors (GEP-NETs) $[3,5,8,12,13,34]$.

All GEP-NETs probably have a malignant potential, but their biological behavior differs from tumor type to tumor type $[9,10,14-17,22,25,26,36]$. Given their rarity [10, 14-17], correct diagnosis and appropriate treatment are often difficult in nonexpert settings and even for appendiceal "carcinoids," probably the best known GEP-NETs with the most benign behavior [31]. Recent data on ileal, appendiceal, and rectal carcinoids, also indicated several variables influencing survival and prognosis [6, 15, 29, 35].

Guidelines for the management of patients with GEPNETs were developed by the recently established European Neuroendocrine Tumor Society (ENETS) [23, 37]. In two separate meetings a consensus was sought on these guidelines. The papers deriving from the first conference dedicated to foregut tumors, including a detailed tumor-nodemetastasis (TNM)/staging and grading proposals, have been published meanwhile [4, 27]. The "Consensus Conference on the ENETS Guidelines for the Diagnosis and Treatment of Neuroendocrine Gastrointestinal Tumors, Part 2: Midgut and Hindgut Tumors" was held in Frascati (Rome, Italy) from November 1 to 4, 2006. In this paper, we present the TNM staging and grading proposals for pure NETs of the lower jejunum/ileum, appendix, and colon/rectum.

\section{Materials and methods}

Fifty-seven experts in the field of GEP-NETs from 18 different countries attended the consensus conference. The attendees represented all medical branches involved in managing patients with GEP-NETs. They formed four working groups according to their specific clinical expertise: (1) pathology and genetics (11 participants, all listed as 
Table 1 Proposal for a TNM classification for endocrine tumors of lower jejunum and ileum

\begin{tabular}{ll}
\hline \multicolumn{2}{c}{ TNM } \\
\hline T-primary tumor \\
TX & Primary tumor cannot be assessed \\
T0 & No evidence of primary tumor \\
T1 & Tumor invades mucosa or submucosa and size $\leq 1 \mathrm{~cm}$ \\
T2 & Tumor invades muscularis propria or size $>1 \mathrm{~cm}$ \\
T3 & Tumor invades subserosa \\
T4 & Tumor invades peritoneum/other organs \\
For any T add (m) for multiple tumors \\
N regional lymph nodes \\
NX & Regional lymph nodes cannot be assessed \\
N0 & No regional lymph node metastasis \\
N1 & Regional lymph node metastasis \\
M & Distant metastasis \\
MX & Distant metastasis cannot be assessed \\
M0 & No distant metastases \\
M1 & Distant metastasis \\
\hline
\end{tabular}

${ }^{a}$ M1 specific sites defined according to Sobin LH, Wittekind C [32].

coauthors), (2) surgery (8 participants), (3) imaging and radiology (7 participants), (4) medicine and clinical pathology (31 participants, including the coauthor B.W.). Most of the participants also attended the first consensus conference held in Frascati in November 2005.

The conference was divided sequentially into five sessions devoted to specific topics on an anatomical basis (ileal welldifferentiated NETs; appendiceal well differentiated NETs; colorectal well differentiated NETs; NETs metastatic to the liver; poorly differentiated neuroendocrine carcinomas of midgut and hindgut origin).

A working booklet with the ENETS guidelines text [23] and specific queries had been prepared in advance by the organizing committee. The work was organized as previously detailed $[4,27]$. This procedure was followed for all five sessions. The TNM staging proposal was prepared by the pathology and genetics working group and amended and approved by the plenary session of the consensus conference. The grading system was mainly discussed and defined by the pathology and genetics working group.

\section{Results and discussion}

The consensus guidelines have been reported elsewhere. The TNM staging proposal for NETs of midgut and hindgut origin together with a grading system is intended to reflect, like its forerunner for the NETs of the stomach, duodenum and pancreas [27], the prognostic assessment by the pathologist. The intestinal NETs were separated into lower jejunum/ileum, appendix, and colon/rectum, but were not
Table 2 Disease staging for endocrine tumors of lower jejunum and ileum

\begin{tabular}{llll}
\hline $\begin{array}{l}\text { Stage } \\
\text { Disease stages }\end{array}$ & $\begin{array}{l}\text { T-primary } \\
\text { tumor }\end{array}$ & $\begin{array}{l}\text { N-regional } \\
\text { nodes }\end{array}$ & $\begin{array}{l}\text { M-distant } \\
\text { metastasis }\end{array}$ \\
\hline Stage I & T1 & N0 & M0 \\
Stage IIA & T2 & N0 & M0 \\
Stage IIB & T3 & N0 & M0 \\
Stage IIIA & T4 & N0 & M0 \\
Stage IIIB & Any T & N1 & M0 \\
Stage IV & Any T & Any N & M1 \\
\hline
\end{tabular}

distinguished according to specific functional activity, main tumor cell type, or genetic background.

TNM staging proposal

The currently published TNM format was adopted as working template (see Tables 1, 2, 3, 4, 5, and 6) [32].

Tumor There is no proposed definition for in situ endocrine tumor of the jejunum, ileum, appendix, colon and rectum, because no specific precursor lesion has been described in the literature so far. For the lower jejunum and ileum, the size limits indicated for $\mathrm{T} 1$ and $\mathrm{T} 2$ are those defined for tumors of "benign behavior" and "uncertain behavior," respectively, according to the WHO site-specific clinicopathological correlations $[5,8,34]$. For the appendix and colon and rectum tumors, lower size limits were defined for $\mathrm{T} 1$ and T2 based on current data [6, 15, 29]. For colon and rectum tumors, $\mathrm{T} 1$ was divided into $\mathrm{T} 1 \mathrm{~A}$ and $\mathrm{T} 1 \mathrm{~B}$ based on current information on the biology of tumors below $1 \mathrm{~cm}$ in size and between 1 and $2 \mathrm{~cm} \mathrm{[6].}$

Deeply invasive and large tumors are included in the T3 and T4 categories, taking into account site-specific features. For any $\mathrm{T}$ definition, the maximum tumor size should be reported and, in the case of multiple lesions, the largest one. The use of T3 category subdivision (pT3a, b, c, and d) according to distance below or higher than $5 \mathrm{~mm}$ from muscularis propria as proposed for the adenocarcinoma [33], could be of value. Its application could be implemented once data on endocrine carcinomas will be generated.

Lymph nodes $\mathrm{N} 1$ indicates the presence of any single or multiple metastases in the regional lymph node group, according to TNM rules. A minimum of 12 nodes should be identified in a surgical specimen, assessed and, when possible, named according to their location in relation to tumor. Although regional lymph node metastases are a negative prognostic factor in GEP-NETs [11], the signifi- 
Table 3 Proposal for a TNM classification for endocrine tumors of the appendix

\begin{tabular}{cc} 
TNM & \\
\hline T-primary tumor \\
TX & Primary tumor cannot be assessed \\
T0 & No evidence of primary tumor \\
T1 & Tumor $\leq 1 \mathrm{~cm}$ invading submucosa and muscularis \\
& propria \\
T2 & Tumor $\leq 2 \mathrm{~cm}$ invading submucosa, muscularis propria \\
& and/or minimally (up to $3 \mathrm{~mm}$ ) invading subserosa/ \\
& mesoappendix \\
T3 & Tumor $>2$ cm and/or extensive (more than $3 \mathrm{~mm}$ ) \\
& invasion of subserosa/mesoappendix \\
T4 & Tumor invades peritoneum/other organs \\
N-regional lymph nodes \\
NX & Regional lymph nodes cannot be assessed \\
N0 & No regional lymph node metastasis \\
N1 & Regional lymph node metastasis \\
M-distant & metastasis \\
MX & Distant metastasis cannot be assessed \\
M0 & No distant metastases \\
M1 & Distant metastasis
\end{tabular}

${ }^{\text {a }}$ M1 specific sites defined according to Sobin LH and Wittekind Ch [32].

cance of the number of metastatic nodes is not yet known. Therefore, similar to the previous foregut TNM proposal, the N1 status in stage IIIB in Tables 1, 2, 3, 4, 5, and 6 has to be specified with regard to the number of lymph nodes involved to allow validation.

Distant metastasis $\mathrm{M} 1$ indicates the presence of any single or multiple metastases at any distant anatomical site (including nonregional nodes). As extrahepatic bone metastases are a negative prognostic factor $[7,21]$, it is recommended to specify the anatomical site of the metastasis according to the TNM classification rules (PUL, pulmonary; HEP, hepatic; OSS, osseous; etc.) [32].

Staging Stage I encompasses the T1 NETs with limited growth. Stage II identifies tumors that are larger in size or more invasive, either $\mathrm{T} 2$ or $\mathrm{T} 3$, although always in the

Table 4 Disease staging for endocrine tumors of the appendix

\begin{tabular}{llll}
\hline $\begin{array}{l}\text { Stage } \\
\text { Disease stages }\end{array}$ & $\begin{array}{l}\text { T-primary } \\
\text { tumor }\end{array}$ & $\begin{array}{l}\text { N-regional } \\
\text { nodes }\end{array}$ & $\begin{array}{l}\text { M-distant } \\
\text { metastasis }\end{array}$ \\
\hline Stage I & T1 & N0 & M0 \\
Stage IIA & T2 & N0 & M0 \\
Stage IIB & T3 & N0 & M0 \\
Stage IIIA & T4 & N0 & M0 \\
Stage IIIB & Any T & N1 & M0 \\
Stage IV & Any T & Any N & M1 \\
\hline
\end{tabular}

Table 5 Proposal for a TNM classification for endocrine tumors of colon and rectum

\section{TNM}

$\begin{array}{ll}\text { T-primary tumor } \\ \text { TX } & \text { Primary tumor cannot be assessed } \\ \text { T0 } & \text { No evidence of primary tumor } \\ \text { T1 } & \text { Tumor invades mucosa or submucosa } \\ & \text { T1a size }<1 \mathrm{~cm} \\ & \text { T1b size } 1-2 \mathrm{~cm} \\ \text { T2 } & \text { Tumor invades muscularis propria or size }>2 \mathrm{~cm} \\ \text { T3 } & \text { Tumor invades subserosa/pericolic/perirectal fat } \\ \text { T4 } & \text { Tumor directly invades other organs/structures and/or } \\ & \text { perforates visceral peritoneum }\end{array}$

For any $\mathrm{T}$ add $(\mathrm{m})$ for multiple tumors

$\mathrm{N}$-regional lymph nodes

$\begin{array}{ll}\text { NX } & \text { Regional lymph node status cannot be assessed } \\ \text { N0 } & \text { No regional lymph node metastasis } \\ \text { N1 } & \text { Regional lymph node metastasis } \\ \text { M-distant } & \text { metastases (subspecification as in small bowel) } \\ \text { MX } & \text { Distant metastasis cannot be assessed } \\ \text { M0 } & \text { No distant metastases } \\ \text { M1 }^{\text {a }} & \text { Distant metastasis }\end{array}$

${ }^{\mathrm{a}} \mathrm{M} 1$ specific sites defined according to Sobin $\mathrm{LH}$ and Wittekind $\mathrm{Ch}$ [32].

absence of metastasis. At stage III, the increased malignancy refers either to invasion into surrounding structures (Stage IIIA) or to the presence of regional node metastases (Stage IIIB). Stage IV always implies the presence of distant metastases.

\section{Grading proposal}

Grading Studies on well-differentiated NETs of midgut and hindgut origin have shown the usefulness of a grading system (see Table 7) $[6,35,36]$. Well-differentiated endocrine tumors with proliferative activity greater than $2 \%$, but below that usually found in poorly differentiated endocrine carcinomas, may have a prognosis intermediate between the " $2 \%$ NETs" and poorly differentiated carcino-

Table 6 Disease staging for endocrine tumors of colon and rectum

\begin{tabular}{llll}
\hline $\begin{array}{l}\text { Stage } \\
\text { Disease stages }\end{array}$ & $\begin{array}{l}\text { T-primary } \\
\text { tumor }\end{array}$ & $\begin{array}{l}\text { N-regional } \\
\text { nodes }\end{array}$ & $\begin{array}{l}\text { M-distant } \\
\text { metastasis }\end{array}$ \\
\hline Stage IA & T1a & N0 & M0 \\
Stage IB & T1b & N0 & M0 \\
Stage IIA & T2 & N0 & M0 \\
Stage IIB & T3 & N0 & M0 \\
Stage IIIA & T4 & N0 & M0 \\
Stage IIIB & Any T & N1 & M0 \\
Stage IV & Any T & Any N & M1 \\
\hline
\end{tabular}


Table 7 Grading proposal for (neuro)endocrine tumors of ileum, appendix, colon and rectum

\begin{tabular}{lll}
\hline Grade & Mitotic count $(10 \mathrm{HPF})^{*}$ & Ki-67 index $(\%)^{* *}$ \\
\hline G1 & $<2$ & $\leq 2$ \\
G2 & $2-20$ & $3-20$ \\
G3 & $>20$ & $>20$
\end{tabular}

* $10 \mathrm{HPF}$ (High Power Field) $=2 \mathrm{~mm}^{2}$, at least 40 fields (at $40 \times$ magnification) evaluated in areas of highest mitotic density; ** MIB1 antibody; \% of 2000 tumor cells in areas of highest nuclear labeling.

mas $[18-20,23,24]$. We decided to follow the same grading system proposal as that devised for foregut tumors, with the aim of distinguishing G2 from G1 and G3 GEPNETs. The three tumor categories are defined as follows: G1, $<2$ mitoses per $2 \mathrm{~mm}^{2}$ (10 high-power fields, HPF, 40× magnification) and/or Ki-67 index $\leq 2 \%$; G2, 2-20 mitoses per $2 \mathrm{~mm}^{2}$ and/or Ki-67 index between 3\% (intended as $>2 \%$ ) and 20\%; G3 with 21 or more mitoses per $2 \mathrm{~mm}^{2}$ and Ki-67 index $>20 \%$.

The G1 and G2 well-differentiated NETs usually display diffuse and intense expression of the two general immunohistochemical neuroendocrine markers, chromogranin A and synaptophysin [28]. Punctate necrosis is per se indicative of a more aggressive tumor and points to a $\mathrm{G} 2$ or G3 status, which is then determined by the mitotic count and the proliferation fraction. G3 indicates a poorly differentiated neuroendocrine carcinoma with high mitotic counts/Ki-67 index, fields of necrosis, significantly reduced chromogranin A expression and intense staining for synaptophysin, meeting the current WHO histological criteria $[5,8,34]$.

Mitotic count and Ki-67 index As for the foregut proposal, mitoses should be counted on hematoxylin and eosin stained slides in at least $40 \mathrm{HPF}$ when possible. The mitoses should be assessed in areas where they are most frequent after a general slide survey. For Ki-67 assessment, the MIB1 antibody is recommended at the conditions that have been established at the laboratory in question. The Ki-67 index should be assessed in 2,000 tumor cells in areas where the highest nuclear labeling is observed (often but not exclusively at the tumor periphery).

\section{Concluding remarks}

The TNM staging system proposed here for midgut and hindgut NETs closely follows its forerunner for foregut tumors [27]. It has the same basis, i.e., the current WHO classifications of GEP-NETs, and results from a consensus conference held by specialists and practicing physicians involved in the management of patients with GEP-NETs. The grading system described here is substantially identical to that proposed for foregut NETs and again attempts to close the gap between the advances of the most recent WHO classifications and the need for a better prognostic assessment of NETs. These proposals, as well as those already published, await confirmation by clinicopathologic work.

Acknowledgements Source of support: grants from MIUR (COFIN 2005) and the University of Parma to GR. The Consensus Conference Part 2 in Frascati was supported by a generous grant to ENETS from Novartis Oncology.

\section{References}

1. Artale S, Giannetta L, Cerea G, Pedrazzoli P, Schiavetto I, Napolitano M, Veronese S, Bramerio E, Gambacorta M, Vanzulli A, Pisconti S, Pugliese R, Siena S (2005) Treatment of metastatic neuroendocrine carcinomas based on WHO classification. Anticancer Res 25:4463-4469

2. Bajetta E, Catena L, Procopio G, Bichisao E, Ferrari L, Della Torre S, De Dosso S, Iacobelli S, Buzzoni R, Mariani L, Rosai J (2005) Is the new WHO classification of neuroendocrine tumours useful for selecting an appropriate treatment? Ann Oncol $16: 1374-1380$

3. Capella C, Heitz PU, Hofler H, Solcia E, Kloppel G (1995) Revised classification of neuroendocrine tumours of the lung, pancreas and gut. Virchows Arch 425:547-560

4. de Herder W, O'Toole D, Rindi G, Wiedenmann B (2006) Consensus Guidelines on the management of patients with digestive neuroendocrine tumors: Why such guidelines and how we went about it. Neuroendocrinology 84:155-157

5. DeLellis RA, Lloyd RV, Heitz PU, Eng C (2004) World health organization classification of tumours, pathology and genetics of tumours of endocrine organs. IARC, Lyon

6. Fahy BN, Tang LH, Klimstra D, Wong WD, Guillem JG, Paty PB, Temple LK, Shia J, Weiser MR (2007) Carcinoid of the rectum risk stratification (CaRRS): A strategy for preoperative outcome assessment. Ann Surg Oncol 14:396-404

7. Gibril F, Doppman JL, Reynolds JC, Chen CC, Sutliff VE, Yu F, Serrano J, Venzon DJ, Jensen RT (1998) Bone metastases in patients with gastrinomas: a prospective study of bone scanning, somatostatin receptor scanning, and magnetic resonance image in their detection, frequency, location, and effect of their detection on management. J Clin Oncol 16:1040-1053

8. Hamilton SR, Aaltonen LA (2000) World health organization classification of tumours, pathology and genetics of tumours of the digestive system. IARC, Lyon

9. Hemminki K, Li X (2001) Familial carcinoid tumors and subsequent cancers: a nation-wide epidemiologic study from Sweden. Int J Cancer 94:444-448

10. Hemminki K, Li X (2001) Incidence trends and risk factors of carcinoid tumors: a nationwide epidemiologic study from Sweden. Cancer 92:2204-2210

11. Jensen RT (1999) Natural history of digestive endocrine tumors. In: Mignon M, Colombel JF (eds) Recent advances in the pathophysiology and management of inflammatory bowel diseases and digestive endocrine tumors. John Libbey Eurotext, Montrouge, London, Rome, pp 192-219

12. Klöppel G (2007) Tumour biology and histopathology of neuroendocrine tumours. Best Pract Res Clin Endocrinol Metab 21:15-31 
13. Klöppel G, Perren A, Heitz PU (2004) The gastroenteropancreatic neuroendocrine cell system and its tumors: the WHO classification. Ann N Y Acad Sci 1014:13-27

14. Maggard MA, O'Connell JB, Ko CY (2004) Updated populationbased review of carcinoid tumors. Ann Surg 240:117-122

15. McGory ML, Maggard MA, Kang H, O'Connell JB, Ko CY (2005) Malignancies of the appendix: beyond case series reports. Dis Colon Rectum 48:2264-2271

16. Modlin IM, Kidd M, Latich I, Zikusoka MN, Shapiro MD (2005) Current status of gastrointestinal carcinoids. Gastroenterology 128:1717-1751

17. Modlin IM, Lye KD, Kidd M (2003) A 5-decade analysis of 13,715 carcinoid tumors. Cancer 97:934-959

18. Öberg K, Astrup L, Eriksson B, Fålkmer SE, Fålkmer UG, Gustafsen J, Haglund C, Knigge U, Vatn MH, Valimaki M (2004) Guidelines for the management of gastroenteropancreatic neuroendocrine tumours (including bronchopulmonary and thymic neoplasms). Part I. General overview. Acta Oncol 43:617-625

19. Öberg K, Astrup L, Eriksson B, Fålkmer SE, Fålkmer UG, Gustafsen J, Haglund C, Knigge U, Vatn MH, Valimaki M (2004) Guidelines for the management of gastroenteropancreatic neuroendocrine tumours (including bronchopulmonary and thymic neoplasms). Part II. Specific NE tumour types. Acta Oncol 43:626-636

20. Öberg K, Kvols L, Caplin M, Delle Fave G, de Herder W, Rindi G, Ruszniewski P, Woltering EA, Wiedenmann B (2004) Consensus report on the use of somatostatin analogs for the management of neuroendocrine tumors of the gastroenteropancreatic system. Ann Oncol 15:966-973

21. Panzuto F, Nasoni S, Falconi M, Corleto VD, Capurso G, Cassetta S, Di Fonzo M, Tornatore V, Milione M, Angeletti S, Cattaruzza MS, Ziparo V, Bordi C, Pederzoli P, Delle Fave G (2005) Prognostic factors and survival in endocrine tumor patients: comparison between gastrointestinal and pancreatic localization. Endocr Relat Cancer 12:1083-1092

22. Pelosi G, Bresaola E, Bogina G, Pasini F, Rodella S, Castelli P, Iacono C, Serio G, Zamboni G (1996) Endocrine tumors of the pancreas: ki-67 immunoreactivity on paraffin sections is an independent predictor for malignancy: a comparative study with proliferating-cell nuclear antigen and progesterone receptor protein immunostaining, mitotic index, and other clinicopathologic variables. Hum Pathol 27:1124-1134

23. Plöckinger U, Rindi G, Arnold R, Eriksson B, Krenning EP, de Herder WW, Goede A, Caplin M, Öberg K, Reubi JC, Nilsson O, Delle Fave G, Ruszniewski P, Ahlman H, Wiedenmann B (2004) Guidelines for the diagnosis and treatment of neuroendocrine gastrointestinal tumours. A consensus statement on behalf of the European Neuroendocrine Tumour Society (ENETS). Neuroendocrinology 80:394-424

24. Ramage JK, Davies AH, Ardill J, Bax N, Caplin M, Grossman A, Hawkins R, McNicol AM, Reed N, Sutton R, Thakker R, Aylwin S, Breen D, Britton K, Buchanan K, Corrie P, Gillams A, Lewington V, McCance D, Meeran K, Watkinson A (2005) Guidelines for the management of gastroenteropancreatic neuroendocrine (including carcinoid) tumours. Gut 54(Suppl 4):iv1-16

25. Rigaud G, Missiaglia E, Moore PS, Zamboni G, Falconi M, Talamini G, Pesci A, Baron A, Lissandrini D, Rindi G, Grigolato P, Pederzoli P, Scarpa A (2001) High resolution allelotype of nonfunctional pancreatic endocrine tumors: Identification of two molecular subgroups with clinical implications. Cancer Res 61:285-292

26. Rindi G, Azzoni C, La Rosa S, Klersy C, Paolotti D, Rappel S, Stölte M, Capella C, Bordi C, Solcia E (1999) ECL cell tumor and poorly differentiated endocrine carcinoma of the stomach: Prognostic evaluation by pathological analysis. Gastroenterology 116:532-542

27. Rindi G, Klöppel G, Alhman H, Caplin M, Couvelard A, de Herder WW, Erikssson B, Falchetti A, Falconi M, Komminoth P, Körner M, Lopes JM, McNicol AM, Nilsson O, Perren A, Scarpa A, Scoazec JY, Wiedenmann B (2006) TNM staging of foregut (neuro)endocrine tumors: a consensus proposal including a grading system. Virchows Arch 449:395-401

28. Rindi G, Villanacci V, Ubiali A (2000) Biological and molecular aspects of gastroenteropancreatic neuroendocrine tumors. Digestion 45:19-26

29. Rossi G, Valli R, Bertolini F, Sighinolfi P, Losi L, Cavazza A, Rivasi F, Luppi G (2003) Does mesoappendix infiltration predict a worse prognosis in incidental neuroendocrine tumors of the appendix? A clinicopathologic and immunohistochemical study of 15 cases. Am J Clin Pathol 120:706-711

30. Ruszniewski P, Ish-Shalom S, Wymenga M, O’Toole D, Arnold R, Tomassetti P, Bax N, Caplin M, Eriksson B, Glaser B, Ducreux M, Lombard-Bohas C, de Herder WW, Delle Fave G, Reed N, Seitz JF, Van Cutsem E, Grossman A, Rougier P, Schmidt W, Wiedenmann B (2004) Rapid and sustained relief from the symptoms of carcinoid syndrome: results from an open 6-month study of the 28-day prolonged-release formulation of lanreotide. Neuroendocrinology 80:244-251

31. Sandor A, Modlin IM (1998) A retrospective analysis of 1570 appendiceal carcinoids. Am J Gastroenterol 93:422-428

32. Sobin LH, Wittekind C (ed) (2002) TNM Classification of malignant tumours. Wiley-Liss, New York

33. Sobin LH, Wittekind C (ed) (2006) TNM Classification of Malignant Tumours, 6th edn. Wiley, New York

34. Solcia E, Klöppel G, Sobin LH (2000) Histological typing of endocrine tumours. Springer, New York

35. Tomassetti P, Campana D, Piscitelli L, Casadei R, Nori F, Brocchi E, Santini D, Pezzilli R, Corinaldesi R (2006) Endocrine tumors of the ileum: factors correlated with survival. Neuroendocrinology 83: 380-386

36. Van Eeden S, Quaedvlieg PF, Taal BG, Offerhaus GJ, Lamers CB, Van Velthuysen ML (2002) Classification of low-grade neuroendocrine tumors of midgut and unknown origin. Hum Pathol 33:1126-1132

37. Wiedenmann B (2004) From ENET to ENETS: a long odyssey in the land of small and rare tumors. Neuroendocrinology 80:1-12 